\title{
Clinical significance of chromatin remodeling factor CHD5 expression in gastric cancer
}

\author{
TADAYOSHI HASHIMOTO ${ }^{1}$, YUKINORI KUROKAWA ${ }^{1}$, NORIKO WADA ${ }^{1}$, \\ TSUYOSHI TAKAHASHI $^{1}$, YASUHIRO MIYAZAKI ${ }^{1}$, KOJI TANAKA ${ }^{1}$, TOMOKI MAKINO ${ }^{1}$, \\ MAKOTO YAMASAKI $^{1}$, KIYOKAZU NAKAJIMA ${ }^{1}$, MASAKI MORI ${ }^{2}$ and YUICHIRO DOKI ${ }^{1}$ \\ ${ }^{1}$ Department of Gastroenterological Surgery, Osaka University Graduate School of Medicine, Osaka 565-0871; \\ ${ }^{2}$ Department of Surgery and Science, Kyushu University Graduate School of Medical Sciences, Fukuoka 812-8582, Japan
}

Received June 3, 2019; Accepted October 8, 2019

DOI: $10.3892 / 01.2019 .11138$

\begin{abstract}
Chromodomain helicase DNA-binding 5 (CHD5), which is a member of the $C H D$ family, has been identified as a tumor suppressor gene in a variety of malignancies. The aim of the current study was to clarify the clinical significance of CHD5 expression in gastric cancer. CHD5 expression was evaluated using immunohistochemistry (IHC) in 154 specimens resected from patients with gastric cancer from January 2011 to December 2013, and assessed its relationships with clinicopathological characteristics and survival. In vitro cell proliferation, invasion, and migration assays and western blotting analysis were performed to clarify the role of CHD5 in human gastric cancer cell lines. Of a total of 154 patients, $57(37.0 \%)$ exhibited low CHD5 expression, which was significantly associated with positive lymphatic invasion $(\mathrm{P}=0.032)$, advanced $\mathrm{pT}$ status $(\mathrm{P}=0.011)$, and advanced $\mathrm{pStage}$ $(\mathrm{P}=0.014)$. Overall survival $(\mathrm{OS})$ in patients with low CHD5 expression was significantly worse compared with patients with high CHD5 expression (hazard ratio, 1.96; 95\% confidence interval, 1.09-3.45; log-rank $\mathrm{P}=0.023$ ). Cox multivariate analysis for OS revealed that CHD5 expression was an independent prognostic factor with age and $\mathrm{pN}$ status. In vitro, the upregulation of CHD5 in gastric cancer cells with low CHD5 expression significantly decreased cell proliferation, migration and invasion. CHD5 was associated with the regulation of multiple cancer-related targets, including p53 and enhancer of zeste homolog 2 (EZH2) in western blotting analysis. In conclusion, since CHD5 regulated multiple cancer-related targets, its expression may be a useful prognostic biomarker in patients with gastric cancer.
\end{abstract}

Correspondence to: Dr Yukinori Kurokawa, Department of Gastroenterological Surgery, Osaka University Graduate School of Medicine, 2-2-E2 Yamadaoka, Suita, Osaka 565-0871, Japan

E-mail: ykurokawa@gesurg.med.osaka-u.ac.jp

Key words: gastric cancer, chromatin remodeling factor, chromodomain helicase DNA-binding 5, immunohistochemistry, biomarker

\section{Introduction}

Gastric cancer remains one of the leading causes of cancer-related deaths worldwide, and the clinical prognosis of advanced gastric cancer remains poor despite multiple treatment options (1-4). Against this background, various studies have been performed to identify useful biomarkers to predict gastric cancer prognosis (5-7). However, unlike HER2, few markers are generally used in clinical practice, and further investigations of novel markers are warranted.

The chromodomain helicase DNA binding 5 (CHD5) gene was first identified because of its distinctive location on the short arm of chromosome $1 \mathrm{p} 36$ in a region of frequent deletion in neuroblastomas $(8,9)$. CHD5 is the fifth of nine members of the $C H D$ family, which is considered to epigenetically regulate chromatin organization and DNA transcription, translation, and replication $(10,11)$. CHD5 has been recognized as a tumor suppressor gene in various malignancies. It has been suggested that CHD5 is frequently down-regulated in tumor cells through promoter hypermethylation, and its decreased expression is associated with unfavorable clinical features and poor outcomes (12-14).

Regarding gastric cancer, several studies investigated the methylation status of $C H D 5$ in gastric cancer cell lines and tissue samples and revealed that CHD5 was down-regulated by promoter hypermethylation (15). However, only a few studies have investigated the clinical implications of CHD5 protein expression in gastric cancer (16), and the mechanism of CHD5 function in gastric cancer has not yet been clarified. In the present study, we used immunohistochemistry (IHC) to investigate the association between CHD5 expression in tissue samples and clinicopathological characteristics in patients with gastric cancer, and clarified the mechanisms underlying the role of CHD5 in tumor progression in gastric cancer cells in vitro.

\section{Materials and methods}

Patients and tissue samples. We collected the data of 154 consecutive patients with cT2-4 gastric cancer between January 2011 and December 2013. Patients who received neoadjuvant chemotherapy or underwent non-curative resection (R2) were excluded. 
All tumors were histologically diagnosed as adenocarcinoma of the stomach. A total of 154 gastric cancer tissue samples were analyzed after written informed consent was obtained from each patient. We used the 14th edition of the Japanese classification of gastric carcinoma to determine the pathological stage (17). The present study was approved by the Institutional Review Board of Osaka University Hospital (approval number: 18227).

Cell lines and cell culture conditions. We used six gastric cancer cell lines, as follows: AGS, KATO III, MKN45, NCI-N87, NUGC-3, and OCUM-1. A human cervical cancer cell line, HeLa, was used as the positive control. AGS, MKN45, OCUM-1, NCI-N87, and NUGC-3 were cultured in Roswell Park Memorial Institute (RPMI) 1640 medium (Nacalai Tesque), HeLa in Dulbecco's modified eagle's medium (DMEM) (Wako Pure Chemical Industries), and KATO III in mixed RPMI 1640 and DMEM (1:1), each containing 10\% fetal bovine serum (FBS; Thermo Fisher Scientific, Inc.). To induce cell growth, all cell lines were incubated in a humidified atmosphere under $5 \% \mathrm{CO}_{2}$ at $37^{\circ} \mathrm{C}$.

Immunohistochemical staining of CHD5. We prepared 3.5- $\mu$ m-thick sections of the resected specimens from formalin-fixed paraffin-embedded blocks. These were deparaffinized with xylene and then rehydrated with multistep descending concentrations of ethanol. The sections were autoclaved in citrate buffer at $115^{\circ} \mathrm{C}$ for $20 \mathrm{~min}$, immersed in $0.3 \%$ hydrogen peroxide to block endogenous peroxidase, and incubated in horse serum for $20 \mathrm{~min}$ to avoid nonspecific staining. The slides were incubated with monoclonal antibody against CHD5 (sc-271248; dilution, 1:500; Santa Cruz Biotechnology, Inc.) overnight at $4^{\circ} \mathrm{C}$, with $\mathrm{ABC}$ peroxidase (Vector Laboratories) for $20 \mathrm{~min}$, and with diaminobenzidine tetrahydrochloride for $1.5 \mathrm{~min}$ to visualize the reactions with CHD5. Normal human Purkinje cells in cerebellum tissue were used as a positive control (Fig. S1). CHD5 expression was evaluated in terms of the percentage and intensity of tumor cells that stained positively for CHD5. As reported previously, the percentage and intensity scores were defined as follows: percentage; $0 \%$, score $0 ; 1-10 \%$, score $1 ; 11-50 \%$, score 2; 51-100\%, score 3; and intensity; negative, score 0; weak, score 1 ; moderate, score 2 ; strong, score $3(18,19)$. The final score was estimated by multiplying both scores and was classified into two groups: the high CHD5 expression group (>3) and the low CHD5 expression group ( $\leq 3)$. Representative IHC staining in each group can be found in Fig. 1.

$R N A$ extraction and quantitative real-time reverse transcription PCR (RT-PCR). Total RNA was extracted from cells and converted to complementary DNA (cDNA). Primers for RT-PCR were as follows: CHD5 forward, CCAGTGGGCACC GAGGAG, and CHD5 reverse, CTTCTTCCGCTTCCCTTT AC. GAPDH was used as an internal control. RT-PCR was carried out with THUNDERBIRD SYBR qPCR Mix (Toyobo Life Science) and the LightCycler 2.0 Instrument (Roche Life Science).

CHD5 up-regulation with the CRISPR/Cas9 system. The clustered regularly interspaced short palindromic repeats (CRISPR)/CRISPR-associated protein (Cas9) system was used to up-regulate CHD5. CHD5 CRISPR Activation Plasmid (CHD5-plasmid) and Control CRISPR Activation Plasmid (Control-plasmid) for negative control (Santa Cruz Biotechnology, Inc.) were used based on the manufacturer's protocol.

Proliferation assay. A proliferation assay was performed using AGS, MKN45, and NUGC-3 gastric cancer cells. Cells were seeded and incubated for $24 \mathrm{~h}$ in 96 -well plates, and then transfected with CHD5-plasmid and Control-plasmid. After transfection, the 3-(4,5-dimethylthiazol-2yl)-2,5-diphenyl tetrazolium bromide (MTT) assay (Sigma-Aldrich) was used to estimate the cell number every $24 \mathrm{~h}$ until cells were confluent.

Migration assay. A wound-healing assay was performed using AGS, MKN45, and NUGC-3 gastric cancer cells. Cells transfected with CHD5-plasmid or Control-plasmid were seeded and incubated until confluent. Cell monolayers were scratched and then incubated in medium with $0.5 \%$ FBS. Every $12 \mathrm{~h}$ after scratching, we evaluated the percent reduction of the scratched area using the scientific image-analysis program, ImageJ (National Institutes of Health, Bethesda).

Invasion assay. We used a Corning BioCoat Matrigel Invasion Chamber (Discovery Labware) to evaluate the invasion abilities of AGS and NUGC-3 gastric cancer cells (20). Cells were cultured in serum-free medium and then transferred to wells filled with medium containing $10 \%$ FBS. After incubation for $24 \mathrm{~h}$ cells that invaded from the culture site to the opposite side of the membrane were fixed and stained with Diff-Quick, and then counted with a microscope.

Western blotting analysis. We extracted proteins from AGS, MKN45, and NUGC-3 gastric cancer cells. Proteins were resolved with SDS-PAGE gels (Bio-Rad Laboratories), transferred onto PVDF membranes (Millipore), and incubated with primary antibodies at $4^{\circ} \mathrm{C}$ overnight. After incubation with secondary antibodies, signals were detected with the ECL Prime Western Blotting Detection reagent (GE Healthcare). The following antibodies (all at 1:1,000 dilution) were used in the present study: ACTB (Sigma-Aldrich), CHD5 (Santa Cruz Biotechnology, Inc.), p53 (DAKO), Murine Double Minute 2 (MDM2; Santa Cruz Biotechnology, Inc.), Enhancer of zeste homologue 2 (EZH2; Invitrogen), and tri-methylation at lysine 27 of histone $\mathrm{H} 3$ (H3K27me3; Abcam).

Statistical analysis. We compared clinicopathological factors using the Chi-squared test for categorical variables and the Mann-Whitney $U$ test for continuous variables. Overall survival (OS) was defined as the time from the date of surgery to the date of death from any cause. Recurrence-free survival (RFS) was defined as the time from the date of surgery to either the date of recurrence or death from any cause. OS and RFS were estimated by the Kaplan-Meier method and tested with the log-rank test. Cox proportional hazards models were used for both univariate and multivariate analyses. A value of $\mathrm{P}<0.05$ was considered to indicate a statistically significant difference. All statistical analyses were performed using the SPSS statistics software program, version 22 (IBM Corp). 
A

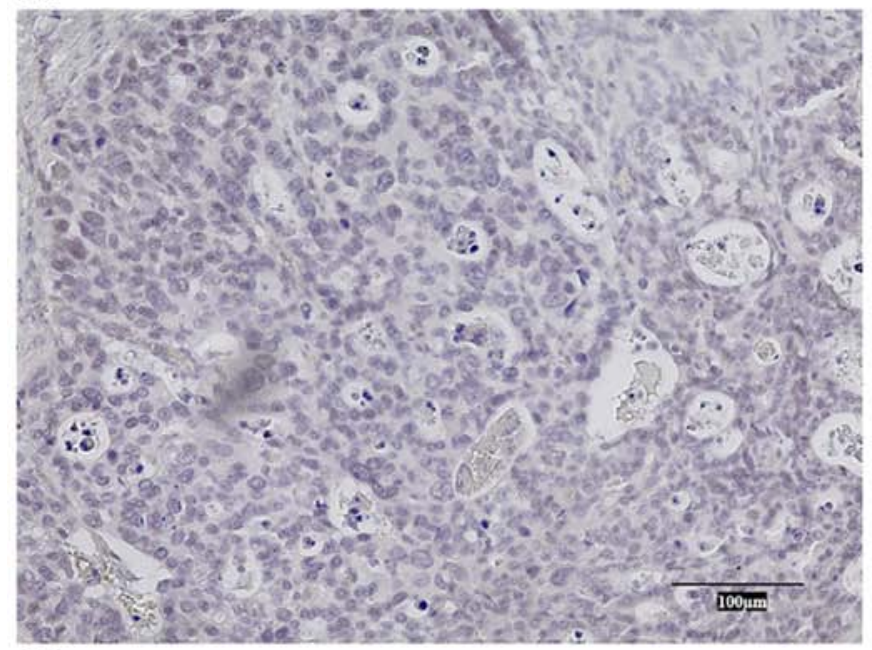

C

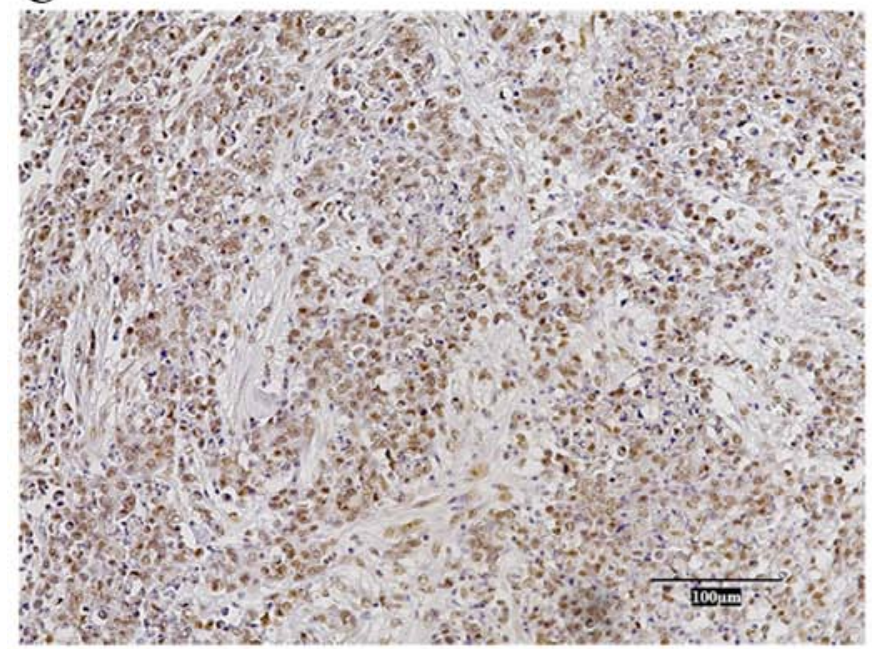

B

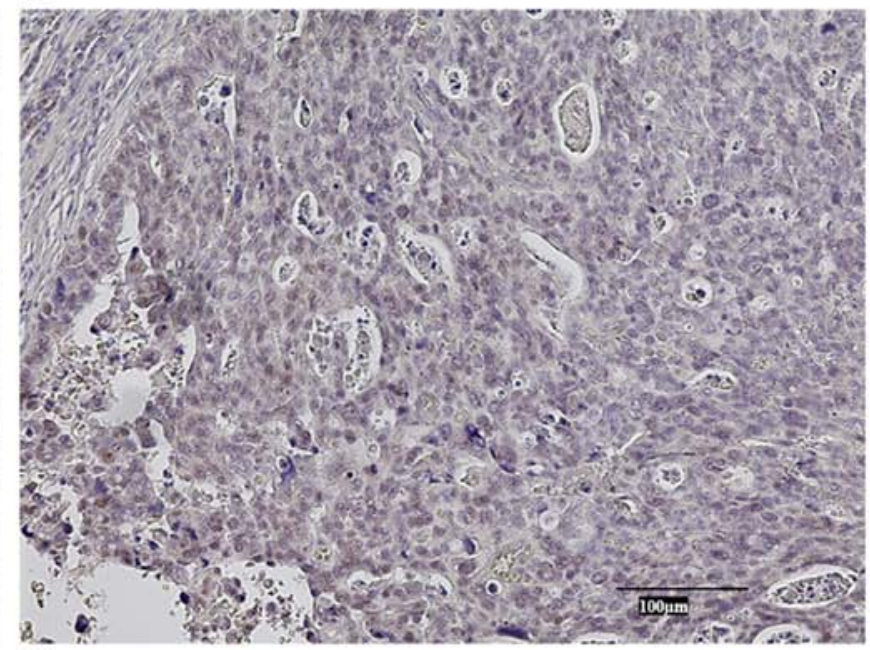

D

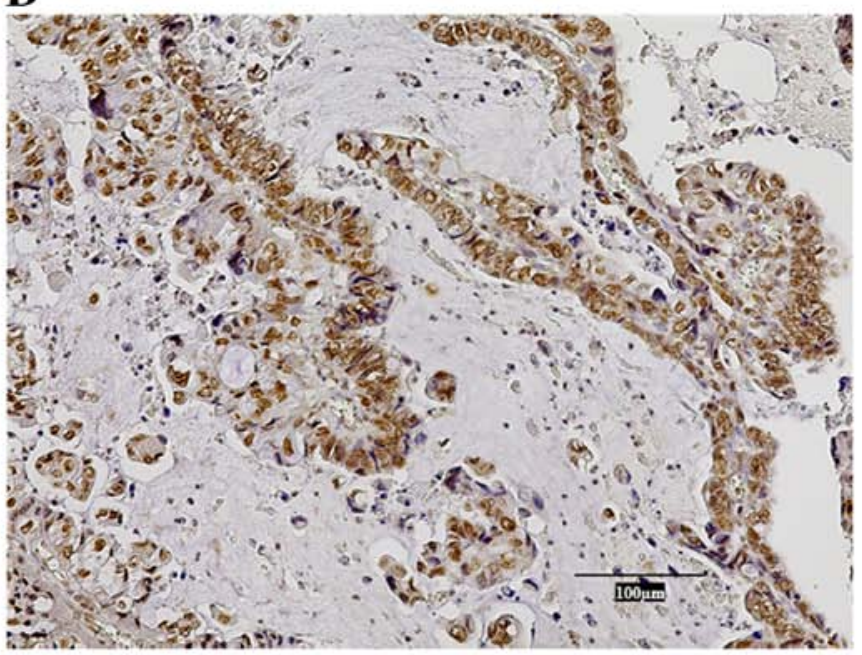

Figure 1. Representative images of CHD5 immunohistochemical staining. (A) Absence of CHD5 nuclear staining in cancer cells, intensity score 0 . (B) Weak CHD5 nuclear staining in cancer cells, intensity score 1. (C) Moderate CHD5 nuclear staining in cancer cells, intensity score 2. (D) Strong CHD5 nuclear staining in cancer cells, intensity score 3 . All images were obtained with an original magnification of x400. CHD5, chromodomain helicase DNA-binding 5 .

\section{Results}

Patient clinicopathological characteristics according to CHD5 expression in gastric cancer tissues. Staining with IHC demonstrated CHD5 in cell nuclei, but also occasionally in the cytoplasm or membrane. Most non-tumor gastric epithelial cells were strongly or moderately stained with the antibody (Fig. S2). Of the tumor tissues, 45 (29.2\%) were negatively or weakly stained, whereas $109(70.8 \%)$ were moderately or strongly stained. After multiplication of the percentage scores, $97(63.0 \%)$ and 57 (37.0\%) of 154 patients showed high and low CHD5 expression, respectively. Clinicopathological characteristics according to CHD5 expression are shown in Table I. Compared to the high CHD5 expression group, a significantly higher proportion of patients in the low CHD5 expression group demonstrated positive lymphatic invasion $(\mathrm{P}=0.032)$ as well as more advanced $\mathrm{pT}$ status $(\mathrm{P}=0.011)$ and $\mathrm{pStage}(\mathrm{P}=0.014)$. There were no significant differences between the two groups in terms of other factors.

Survival analysis according to CHD5 expression. The OS and RFS at the median follow-up durations for all censored patients was 60.9 and 61.1 months, respectively. OS in the low CHD5 expression group was significantly shorter than that in the high CHD5 expression group (hazard ratio [HR], 1.96; 95\% confidence interval [CI], 1.09-3.45; log-rank $\mathrm{P}=0.023$; Fig. 2A). Similarly, RFS in the low CHD5 expression group was significantly shorter than that in the high CHD5 expression group (HR, 2.04; 95\% confidence interval [CI], 1.23-3.46; log-rank $\mathrm{P}=0.004$; Fig. 2B).

A Cox multivariate analysis for OS using all considerable confounding factors showed that CHD5 expression was an independent prognostic factor, along with age and pathological $\mathrm{N}$ status (Table II).

CHD5 baseline expression and up-regulation using the CRISPR/Cas 9 system in gastric cancer cells. The expression of CHD5 in gastric cancer cell lines was determined by quantitative RT-PCR. Although CHD5 was expressed in HeLa cells, its expressions in six gastric cancer cell lines (AGS, KATO III, MKN45, NCI-N87, NUGC-3, and OCUM-1) were down-regulated (Fig. 3A). After transfecting AGS, MKN45, and NUGC-3 cells with CHD5-plasmid, CHD5 expression 
Table I. Clinicopathologic characteristics of gastric cancer patients according to CHD5 expression.

\begin{tabular}{|c|c|c|c|}
\hline \multirow[b]{2}{*}{ Characteristics } & \multicolumn{2}{|c|}{ CHD5 expression } & \multirow[b]{2}{*}{ P-value } \\
\hline & High $(n=97)$ & Low $(n=57)$ & \\
\hline Age (years) & & & 0.15 \\
\hline Median (range) & $71(40-90)$ & $68(30-88)$ & \\
\hline Sex & & & 0.21 \\
\hline Male & $70(72.1 \%)$ & $35(61.4 \%)$ & \\
\hline Female & $27(27.9 \%)$ & $22(38.6 \%)$ & \\
\hline Histological type & & & 0.74 \\
\hline Differentiated & $46(47.4 \%)$ & $29(50.9 \%)$ & \\
\hline Undifferentiated & $51(52.6 \%)$ & $28(49.1 \%)$ & \\
\hline $\begin{array}{l}\text { Lymphatic } \\
\text { invasion }\end{array}$ & & & 0.032 \\
\hline Yes & $68(70.1 \%)$ & $49(86.0 \%)$ & \\
\hline No & $29(29.9 \%)$ & $8(14.0 \%)$ & \\
\hline Venous invasion & & & 0.067 \\
\hline Yes & $30(30.9 \%)$ & $26(45.6 \%)$ & \\
\hline No & $67(69.1 \%)$ & $31(54.4 \%)$ & \\
\hline pT status & & & 0.011 \\
\hline $\mathrm{T} 1$ & $27(27.8 \%)$ & $6(10.5 \%)$ & \\
\hline $\mathrm{T} 2$ & $14(14.4 \%)$ & $13(22.8 \%)$ & \\
\hline $\mathrm{T} 3$ & $42(43.2 \%)$ & $21(36.8 \%)$ & \\
\hline $\mathrm{T} 4$ & $14(14.4 \%)$ & $17(29.8 \%)$ & \\
\hline pN status & & & 0.12 \\
\hline N0 & $53(54.6 \%)$ & $26(45.6 \%)$ & \\
\hline N1 & $15(15.5 \%)$ & $7(12.3 \%)$ & \\
\hline N2 & $18(18.6 \%)$ & $9(15.8 \%)$ & \\
\hline N3 & $11(11.3 \%)$ & $15(26.3 \%)$ & \\
\hline pStage & & & 0.014 \\
\hline $\mathrm{I}$ & $26(26.8 \%)$ & $11(19.3 \%)$ & \\
\hline II & $48(49.5 \%)$ & $20(35.1 \%)$ & \\
\hline III & $20(20.6 \%)$ & $18(31.6 \%)$ & \\
\hline IV & $3(3.1 \%)$ & $8(14.0 \%)$ & \\
\hline
\end{tabular}

TNM staging was according to the 14th edition of the Japanese classification of gastric carcinoma. CHD5, Chromodomain helicase DNA-binding 5.

was up-regulated in comparison with cells transfected with Control-plasmid (Fig. 3B).

Proliferation, migration, and invasion assays in gastric cancer cells. We assessed the effects of CHD5 up-regulation by the CRISPR/Cas9 system on the proliferation, migration, and invasion of gastric cancer cell lines. The proliferation assay showed that cell growth abilities in AGS, MKN45, and NUGC-3 cells with up-regulated CHD5 following CHD5-plasmid transfection were significantly inhibited compared to cells transfected with Control-plasmid (Fig. 4A). Next, the scratch wound-healing assay showed that cell migration abilities of AGS, MKN45, and NUGC-3 cells
Table II. Cox multivariate analysis of overall survival.

\begin{tabular}{|c|c|c|}
\hline Characteristics & $\begin{array}{c}\text { Hazard ratio } \\
(95 \% \mathrm{CI})\end{array}$ & P-value \\
\hline Age (years) & & 0.001 \\
\hline$<70$ & 1 & \\
\hline$\geq 70$ & $2.91(1.54-5.50)$ & \\
\hline Sex & & 0.71 \\
\hline Female & 1 & \\
\hline Male & $1.13(0.59-2.14)$ & \\
\hline \multicolumn{3}{|l|}{ Histological type } \\
\hline Differentiated & 1 & 0.21 \\
\hline Undifferentiated & $1.48(0.80-2.75)$ & \\
\hline Lymphatic invasion & & 0.16 \\
\hline No & 1 & \\
\hline Yes & $1.77(0.79-3.92)$ & \\
\hline Venous invasion & & 0.44 \\
\hline No & 1 & \\
\hline Yes & $1.28(0.69-2.38)$ & \\
\hline Pathological T status & & 0.13 \\
\hline$<\mathrm{T} 3$ & 1 & \\
\hline$\geq \mathrm{T} 3$ & $1.65(0.86-3.15)$ & \\
\hline Pathological N status & & 0.001 \\
\hline NO & 1 & \\
\hline N1-3 & $3.65(1.72-7.72)$ & \\
\hline CHD5 expression & & 0.009 \\
\hline High & 1 & \\
\hline Low & $2.25(1.23-4.10)$ & \\
\hline
\end{tabular}

95\% CI, 95\% confidence interval; CHD5, Chromodomain helicase DNA-binding 5.

were significantly suppressed following CHD5 up-regulation (Fig. 4B). Finally, the Matrigel invasion assay showed that invasion abilities of AGS and NUGC-3 cells were significantly decreased following CHD5 up-regulation (Fig. 4C).

Western blotting analysis of multiple cancer genes regulated by CHD5. We examined the protein expression levels of multiple cancer genes, including oncogenes (MDM2, p53) and epigenetic master genes (EZH2, H3K27me3), in AGS, NUGC-3, and MKN45 cells transfected with CHD5-plasmid or Control-plasmid. Western blotting showed that the expression levels of MDM2, EZH2, and H3K27me3 were decreased in CHD5-transfected gastric cancer cells, while the expression level of p53 was increased in CHD5-transfected gastric cancer cells (Fig. S3).

\section{Discussion}

In the present study, we performed IHC in gastric cancer specimens and revealed that the low CHD5 expression group was significantly more likely to exhibit lymphatic invasion, more advanced tumor stage, and worse prognosis than the 
A

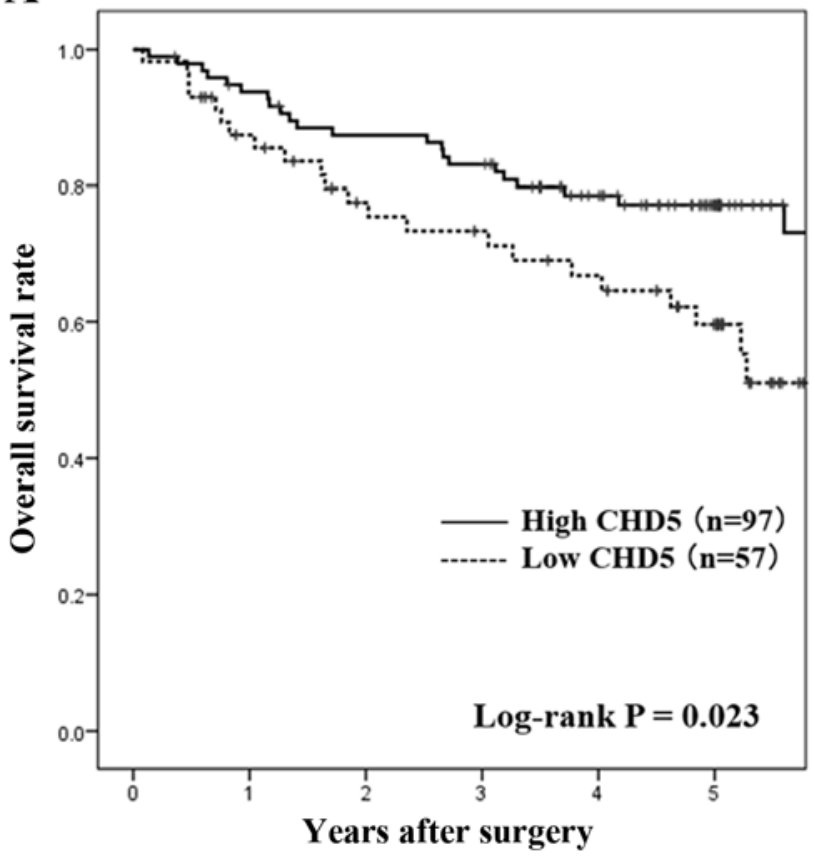

B

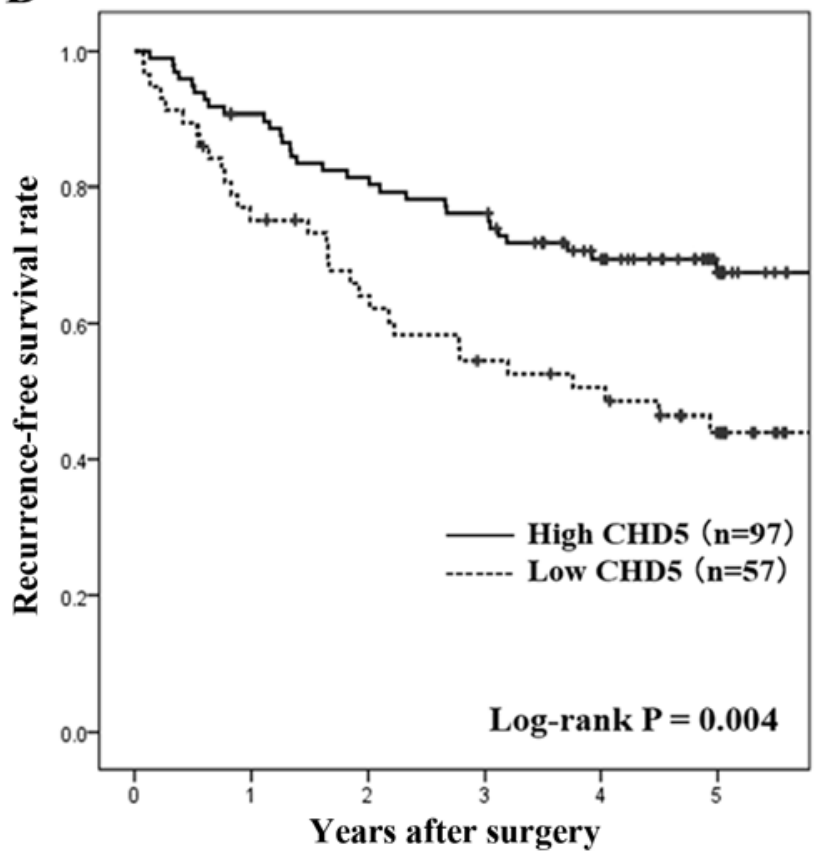

Figure 2. Kaplan-Meier survival of patients with gastric cancer according to CHD5 expression. (A) Overall survival and (B) recurrence-free survival. CHD5, chromodomain helicase DNA-binding 5.

A

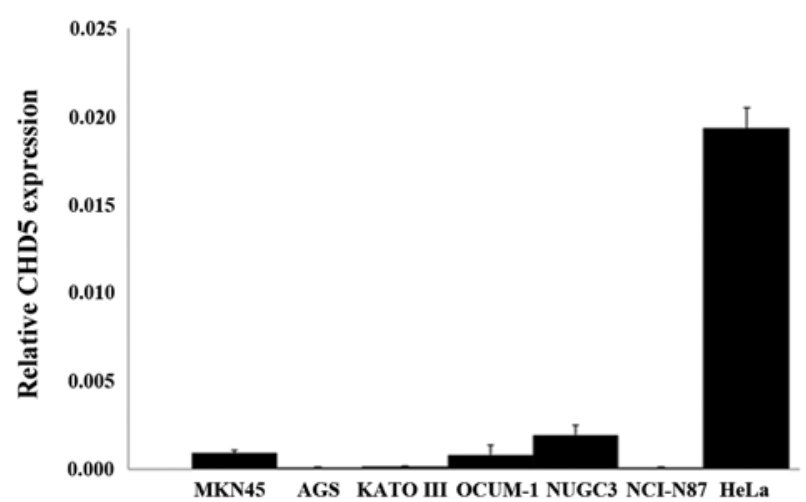

B

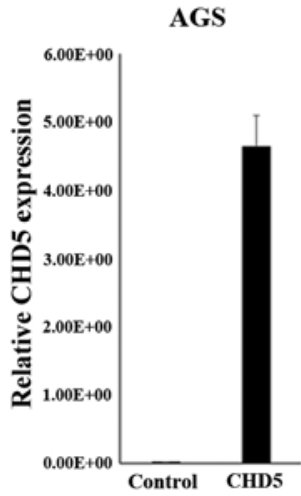

NUGC3

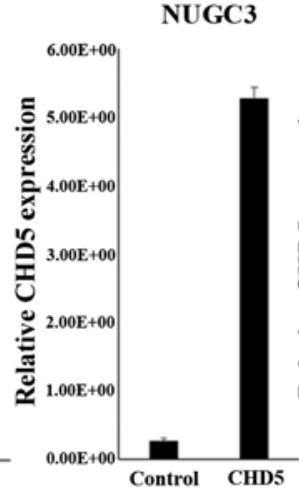

MKN45

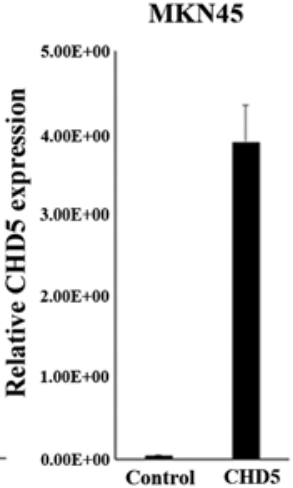

Figure 3. The RNA expression of CHD5 in gastric cancer cell lines was determined using reverse transcription-quantitative PCR. (A) GAPDH was used to normalize the CHD5 expression and HeLa was used as the reference. (B) CHD5 was upregulated by the CRISPR/Cas9 system in gastric cancer cell lines AGS, NUGC-3 and MKN45. CHD5, chromodomain helicase DNA-binding 5.

high CHD5 expression group, and CHD5 expression was an independent prognostic factor for gastric cancer. Furthermore, we found that in vitro up-regulation of CHD5 with the CRISPR/Cas9 system suppressed the proliferation, migration, and invasion abilities of gastric cancer cells. We also showed in western blotting analysis that the up-regulation of CHD5 suppressed the transcription of multiple targets, including MDM2, EZH2, and H3K27me3, but up-regulated p53. Thus, CHD5 is considered to be a tumor suppressor in gastric cancer and its expression in tissue samples may be a novel biomarker to predict prognosis in gastric cancer patients.

Previous studies reported that low CHD5 protein expression was an independent predictive marker for poor prognosis in patients with a variety of malignancies , including glioma, neuroblastoma, pancreatic cancer, and lung cancer $(18,19,21,22)$. Meanwhile, in gastric cancer, few studies have investigated the protein expression of CHD5 in tumor samples, although several studies reported that CHD5 was down regulated through promoter hypermethylation and might function as a tumor suppressor in gastric cancer cell lines $(16,23)$. Our results support those of previous reports and indicate that IHC of CHD5 may be clinically useful to more accurately characterize patients with gastric cancer.

As for the mechanisms of CHD5 down-regulation, many studies revealed that $C H D 5$ was transcriptionally silenced by DNA methylation of its promoter, silencing the remaining allele in some cancers with $1 p$ deletion (24-26). Indeed, it was reported that in various cancers, the promoter of $\mathrm{CHD} 5$ was more heavily methylated than those of the remaining genes in 

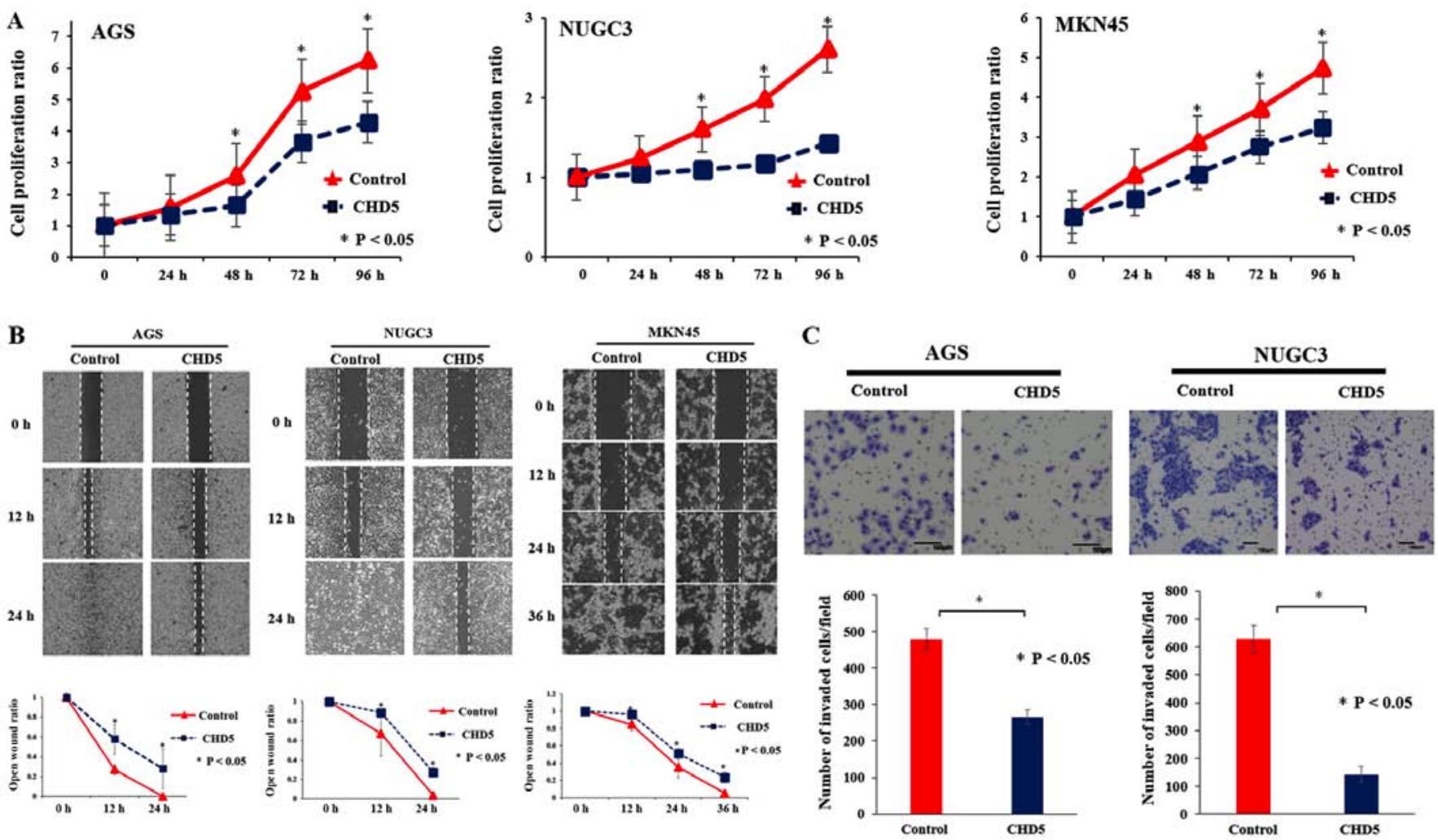

Figure 4. (A) Cell proliferation assay of gastric cancer cell lines AGS, NUGC-3 and MKN45, comparing CHD5- and control-transfected cells. Gastric cancer cells transfected with CHD5-plasmid have significantly decreased proliferation at 48,72 and $96 \mathrm{~h}$ compared with transfected with Control-plasmid. A total of 8 samples were used for each experiment. (B) Scratch wound-healing assay of gastric cancer cell lines (AGS, NUGC-3 and MKN45), comparing CHD5- and control-transfected cells. CHD5-transfected cells have significantly less ability to heal the artificial wound than control-transfected cells at 12, 24 and $36 \mathrm{~h}$. A total of 5 samples were used for each experiment. (C) Invasion assay of gastric cancer cell lines (AGS and NUGC-3), comparing CHD5- and control-transfected cells. CHD5-transfected cells demonstrated significantly less invasion than control-transfected cells. Three samples were used for each experiment. "P<0.05. CHD5, chromodomain helicase DNA-binding 5.

the $C H D$ family (27). Also, regarding gastric cancer, CHD5 was reported to be down regulated through promoter hypermethylation in cell lines and tissue samples as described above. In the present study, all gastric cancer cell lines, including those whose methylation status has already been examined, showed suppressed CHD5 expression, with promoter methylation speculated to be the cause.

Additionally, the functional role of CHD5 has been explored in several malignancies and it has been characterized as a tumor suppressor gene, although the detailed mechanism remains unclear. First, Bagchi et al suggested that CHD5 regulated proliferation, apoptosis, and senescence through the p19(Arf)-p53 tumor suppressor pathway in a mouse model (12). In pancreatic cancer, Hall et al showed that low CHD5 expression prolonged cancer survival by activating the DNA damage response, and was a poor prognostic factor in patients with pancreatic cancer treated with adjuvant chemotherapy (19). Furthermore, in renal cell carcinoma, Du et al. proposed that CHD5 might epigenetically down-regulate the expression of various cancer-related targets, such as oncogenes, epigenetic genes, epithelial-mesenchymal transition factors, and stem cell markers, by binding to their promoter areas (28). In addition, several recent studies reported that some kinds of microRNA represented a potential epigenetic mechanism to regulate CHD5 expression $(16,29)$. Against this background, we used western blotting analysis to examine the p53 pathway, which has been most commonly suggested to be associated with CHD5, and $\mathrm{EZH} 2$, which is a primary epigenetic regulator of various tumor suppressor genes (30). Additionally, several studies reported the mutual regulation of CHD5 and EZH2 (31). We found that CHD5 up-regulation was associated with up-regulation of p53 and down-regulation of EZH2. Based on these results, we hypothesize that down-regulation of CHD5 might promote gastric cancer tumorigenesis by down-regulating $\mathrm{p} 53$, one of the most important tumor suppressor genes, and up-regulating EZH2, thereby suppressing various tumor suppressor genes.

The present study has several limitations. First, it was a retrospective study conducted at a single institution. However, we collected the data of consecutive patients, and we therefore believe that the issue of selection bias was minimized. Second, we only assessed CHD5 in terms of proliferation, inhibitory migration, and invasion. Further research is needed to yield more detailed findings about the roles of CHD5. Third, we used western blotting to examine the expression levels of only a limited number of cancer-related genes and tumor suppressor genes. In the future, it may be necessary to investigate other pathways and determine the precise mechanisms of CHD5 in gastric cancer.

To the best of our knowledge, this is the first study to investigate the clinical implications of CHD5 expression and its functions as a tumor suppressor in gastric cancer. In conclusion, our study suggested that CHD5 expression affects 
cancer malignancy and prognosis by regulating oncogenes and epigenetic modifiers in gastric cancer. CHD5 might function as a tumor suppressor, and assessing its expression using IHC may be a useful prognostic biomarker in gastric cancer.

\section{Acknowledgements}

Not applicable.

\section{Funding}

No funding was received.

\section{Availability of data and materials}

The datasets used and/or analyzed during the current study are available from the corresponding author on reasonable request.

\section{Authors' contributions}

TH, YK, NW, and YD conceived and designed the study. TH and YK analyzed the data and wrote the manuscript. TT, YM, $\mathrm{KT}, \mathrm{TM}, \mathrm{MY}, \mathrm{KN}$ and MM interpreted the data, were involved in drafting the manuscript and revising it critically for important intellectual content. All authors read and approved the final manuscript and agree to be accountable for all aspects of the research in ensuring that the accuracy or integrity of any part of the work are appropriately investigated and resolved.

\section{Ethics approval and consent to participate}

The present study was approved by the Institutional Review Board of Osaka University Hospital (approved no. 18227), and it conforms to the provisions of the Declaration of Helsinki. Informed consent was obtained from all individuals in the current study.

\section{Patient consent for publication}

Not applicable.

\section{Competing interests}

The authors declare that they have no competing interests.

\section{References}

1. Torre LA, Bray F, Siegel RL, Ferlay J, Lortet-Tieulent J and Jemal A: Global cancer statistics, 2012. CA Cancer J Clin 65: 87-108, 2015.

2. Kurokawa Y, Doki Y, Mizusawa J, Terashima M, Katai H, Yoshikawa T,Kimura Y, TakiguchiS, Nishida Y,Fukushima N, et al: Bursectomy versus omentectomy alone for resectable gastric cancer (JCOG1001): A phase 3, open-label, randomised controlled trial. Lancet Gastroenterol Hepatol 3: 460-468, 2018.

3. Colvin H, Mizushima T, Eguchi H, Takiguchi S, Doki Y and Mori M: Gastroenterological surgery in Japan: The past, the present and the future. Ann Gastroenterol Surg 1: 5-10, 2017.

4. Hashimoto T, Kurokawa Y, Mori M, et alUpdate on the Treatment of gastric cancer. JMA J 1: 40-9, 2018.

5. Bang YJ, Van Cutsem E, Feyereislova A, Chung HC, Shen L, Sawaki A, Lordick F, Ohtsu A, Omuro Y, Satoh T, et al: Trastuzumab in combination with chemotherapy versus chemotherapy alone for treatment of HER2-positive advanced gastric or gastro-oesophageal junction cancer (ToGA): A phase 3, openlabel, randomized controlled trial. Lancet 376: 687-697, 2010.
6. Bartley AN and Hamilton SR: Select biomarkers for tumors of the gastrointestinal tract: Present and future. Arch Pathol Lab Med 139: 457-468, 2015.

7. Hashimoto T, Kurokawa Y, Takahashi T, Miyazaki Y, Tanaka K, Makino T, Yamasaki M, Nakajima K, Ikeda JI, Mori M and Doki Y: Predictive value of MLH1 and PD-L1 expression for prognosis and response to preoperative chemotherapy in gastric cancer. Gastric Cancer 22: 785-792, 2019

8. Thompson PM, Gotoh T, Kok M, White PS and Brodeur GM: CHD5, a new member of the chromodomain gene family, is preferentially expressed in the nervous system. Oncogene 22: 1002-1011, 2003.

9. Okawa ER, Gotoh T, Manne J, Igarashi J, Fujita T, Silverman KA, Xhao H, osse YP, White PS and Brodeur GM: Expression and sequence analysis of candidates for the $1 \mathrm{p} 36.31$ tumor suppressor gene deleted in neuroblastomas. Oncogene 27: 803-810, 2008.

10. Kolla V, Zhuang T, Higashi M, Naraparaju K and Brodeur GM: Role of CHD5 in human cancers: 10 years later. Cancer Res 74: 652-658, 2014

11. Oliver SS, Musselman CA, Srinivasan R,Svaren JP,Kutateladze TG and Denu JM: Multivalent recognition of histone tails by the PHD fingers of CHD5. Biochemistry 51: 6534-6544, 2012.

12. Bagchi A, Papazoglu C, Wu Y, Capurso D, Brodt M, Francis D, Bredel M, Vogel H and Mills AA: CHD5 is a tumor suppressor at human 1p36. Cell 128: 459-475, 2007.

13. Mulero-Navarro S and Esteller M: Chromatin remodeling factor CHD5 is silenced by promoter $\mathrm{CpG}$ island hypermethylation in human cancer. Epigenetics 3: 210-215 2008.

14. Baykara O, Tansarikaya M, Bulut P, Demirkaya A and Buyru N: CHD5 is a potential tumor suppressor in non small cell lung cancer (NSCLC). Gene 618: 65-68, 2017.

15. Wang X, Lau KK, So LK and Lam YW: CHD5 is down-regulated through promoter hypermethylation in gastric cancer. J Biomed Sci 16: 95, 2009.

16. Xu G, Zhu H, Zhang M and Xu J: Histone deacetylase 3 is associated with gastric cancer cell growth via the miR-454-mediated targeting of CHD5. Int J Mol Med 41: 155-163, 2018.

17. Japanese Gastric Cancer Association: Japanese classification of gastric carcinoma: 3rd English edition. Gastric Cancer 14: 101-112, 2011.

18. Wang L, He S, Tu Y, Ji P, Zong J, Zhang J, Feng F, Zhao J, Gao G and Zhang Y: Downregulation of chromatin remodeling factor CHD5 is associated with a poor prognosis in human glioma. J Clin Neurosci 20: 958-963, 2013.

19. Hall WA, Petrova AV, Colbert LE, Hardy CW, Fisher SB, Saka B, Shelton JW, Warren MD, Pantazides BG, Gandhi K, et al: Low CHD5 expression activates the DNA damage response and predicts poor outcome in patients undergoing adjuvant therapy for resected pancreatic cancer. Oncogene 33: 5450-5456, 2013.

20. Yamamoto M, Takahashi T, Serada S, Sugase T, Tanaka K, Miyazaki Y,MakinoT,Kurokawa Y, Yamasaki M,Nakajima K, et al: Overexpression of leucine-rich $\alpha 2$-glycoprotein-1 is a prognostic marker and enhances tumor migration in gastric cancer. Cancer Sci 108: 2052-2060, 2017.

21. Garcia I, Mayol G, Rodriguez E, Suñol M, Gershon TR, Ríos J, Cheung NK, Kieran MW, George RE, Perez-Atayde AR, et al: Expression of the neuron-specific protein CHD5 is an independent marker of outcome in neuroblastoma. Mol Cancer 9: 277, 2010

22. Zhao R, Yan Q, Lv J, Huang H, Zheng W, Zhang B and Ma W: CHD5, a tumor suppressor that is epigenetically silenced in lung cancer. Lung Cance 76: 324-331, 2012.

23. Qu Y, Dang S and Hou P: Gene methylation in gastric cancer Clin Chim Acta 424: 53-65, 2013.

24. Wu X, Zhu Z, Li W, Fu X, Su D, Fu L, Zhang Z, Luo A, Sun X, $\mathrm{Fu}$ L and Dong JT: Chromodomain helicase DNA binding protein 5 plays a tumor suppressor role in human breast cancer. Breast Cancer Res 14: R73, 2012.

25. Fatemi M, Paul TA, Brodeur GM, Shokrani B, Brim H and Ashktorab $\mathrm{H}$ : Epigenetic silencing of $\mathrm{CHD} 5$, a novel tumor-suppressor gene, occurs in early colorectal cancer stages. Cancer 120: 172-180, 2014.

26. Wong RR, Chan LK, Tsang TP, Lee CW, Cheung TH, Yim SF, Siu NS, Lee SN, Yu MY, Chim SS, et al: CHD5 downregulation associated with poor prognosis in epithelial ovarian cancer. Gynecol Obstet Invest 72: 203-207, 2011.

27. Fujita T, Igarashi J, Okawa ER, Gotoh T, Manne J, Kolla V, Kim J, Zhao H, Pawel BR, London WB, et al: CHD5, a tumor suppressor gene deleted from $1 \mathrm{p} 36.31$ in neuroblastomas. J Natl Cancer Inst 100: 940-949, 2008. 
28. Du Z, Li L, Huang X, Jin J, Huang S, Zhang Q and Tao Q: The epigenetic modifier CHD5 functions as a novel tumor suppressor for renal cell carcinoma and is predominantly inactivated by promoter CpG methylation. Oncotarget 7: 21618-216130, 2016.

29. Naraparaju K, Kolla V, Zhuang T, Higashi M, Iyer R, Kolla S, Okawa ER, Blobel GA and Brodeur GM: Role of microRNAs in epigenetic silencing of the CHD5 tumor suppressor gene in neuroblastomas. Oncotarget 7: 15977-15985, 2016.
30. Kim KH and Roberts CW: Targeting EZH2 in cancer. Nat Med 22: 128-134, 2016.

31. Xie CR, Li Z, Sun HG, Wang FQ, Sun Y, Zhao WX, Zhang S, Zhao WX, Wang XM and Yin ZY: Mutual regulation between CHD5 and EZH2 in hepatocellular carcinoma. Oncotarget 6: 40940-40952, 2015. 